\title{
NOTE
}

\section{Community structure of sand-dwelling macrofauna of an estuarine beach in Goa, India}

\author{
S. N. Harkantra \& A. H. Parulekar
}

National Institute of Oceanography, Dona Paula 403 004, Goa, India

ABSTRACT: Within the sand-dwelling macroinvertebrate community at Siridao beach, Goa, polychaetes and bivalves dominated in terms of number of species and population density, respectively. Among these Donax faba constituted $34.78 \%$, Scottolana sp. $19.78 \%$, Nerine cirratulus $16.90 \%$, Dotilla myctiroides $5.84 \%$ and Glycera alba $4.56 \%$. Community indices increased from high to low water mark: maximum spatial and temporal species diversities were 3.48 near the low water mark and 3.49 in January 1982, respectively. Dominance of D. myctiroides (in April 1981 and 1982) and D. faba (in February-March 1981 and 1982) indicated the programmed reproductive periodicity in the concerned species. Zonation of macrofauna and co-existence of species were discernible by cluster analysis.

Analysis of community structure is important not only for an understanding of the magnitude of production and energy pathways, but also in evaluating environmental and man-made changes on biota, and further in the management and conservation of the environment. Such studies on estuarine beaches of India are rather few. Some aspects of benthic community structural analysis of sand-dwelling macro-invertebrates from an estuarine beach at Siridao, Goa, India (Fig. 1) are presented and discussed in this paper. The study area - Siridao Beach, and estuarine sheltered foreshore - has a tropical climate characterized by south-west monsoon (June to September), post-monsoon (October to January) and premonsoon (February to May). Most of the rainfall occurs during the monsoon with an annual average of $3000 \mathrm{~mm}$. Heavy swells and beach erosion occur during this period. The tides are semi-diurnal $\mathrm{M}_{2}$ type (Davies 1972) with a maximum tidal amplitude of about $2.3 \mathrm{~m}$ and intertidal width of about 40 to $50 \mathrm{~m}$. Some of the environmental characteristics of the study area were as follows. Particle size varied from 0.43 to $0.10 \mathrm{~mm}$ showing medium to very fine sand. Salinity, temperature, chlorophyll a (surf waters), and organic carbon of the sand varied from

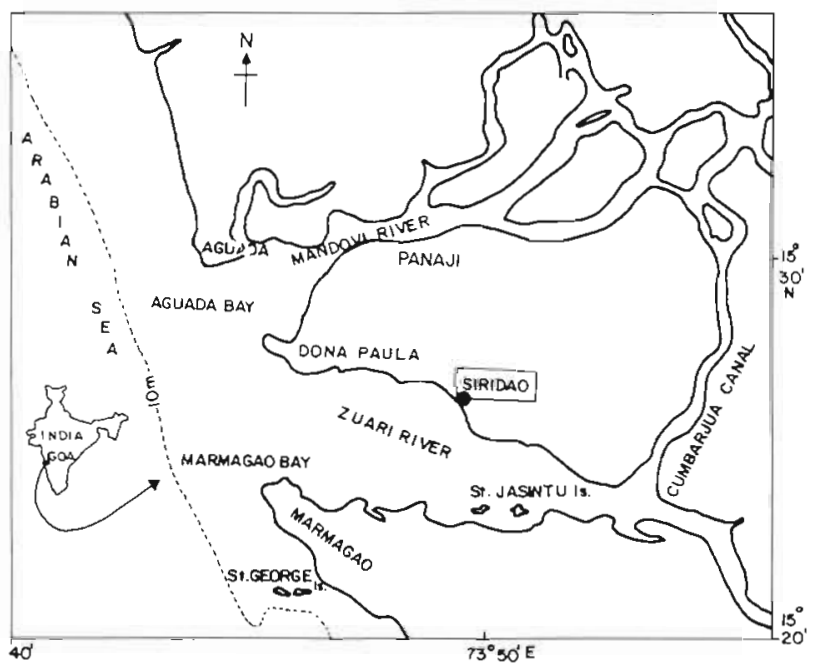

Fig. 1. Map showing location of study area at Siridao

3.40 (July) to $33.32 \%$ (May), 24.6 to $31.6{ }^{\circ} \mathrm{C}, 0.54$ to $9.75 \mu \mathrm{g} \mathrm{l}^{-1}$ and 0.69 to $2.35 \mathrm{mg} \mathrm{g}^{-1}$, respectively (Harkantra 1984).

Macrobenthic samples were collected at $10 \mathrm{~m}$ intervals from high $(0 \mathrm{~m})$ to low $(50 \mathrm{~m})$ water mark along a transect perpendicular to the beach. Collections were undertaken during the low tide at monthly intervals from January 1981 to May 1982. A metallic quadrat covering a surface area of $0.0625 \mathrm{~m}^{2}$ and penetrating $20 \mathrm{~cm}$ into the sediment was used. The enclosed sand was scooped by shovel and washed through a $0.5 \mathrm{~mm}$ mesh screen, and retained samples were preserved in $10 \%$ seawater rose-bengal formalin. Faunal samples were sorted and counted by species under a stereozoom binocular microscope and converted to individuals $\mathrm{m}^{-2}$. Diversity indices were computed according to Pielou (1975). Species rank abundances (SRA) was arranged in order of numerical abundance (Pielou 1975). Sites or months were classified by using 
the Bray-Curtis index (Clifford \& Sephenson 1975). Raw data were transformed logarithmically into ln $(\mathrm{x}+1)$ and group average clustering strategies were used (Sokal \& Sneath 1963). The resulting dendrograms derived from normal analysis were evaluated using variable stopping rule group (Boesch 1973). All analyses were carried out on a TDC-316 computer (ECIL).

From this beach 35 species of macro-invertebrates, belonging to 12 major taxa, have been reported earlier (Harkantra \& Parulekar 1984). Bivalvia (35.83\%) and Polychaeta $(25.65 \%)$ formed the dominant and codominant taxa in order of faunal composition. The number of polychaete species was the highest, compared to other groups. Earlier workers (McIntyre 1968, Philip 1974, Croker 1977, Dexter 1979) also noted high numbers of polychaete species on estuarine beaches as compared to open beaches. Composition by numbers of individuals of each species showed dominancy of Bivalvia (Donax faba, $34.78 \%$ ), followed by Harpacticoida (Scottolana sp., $19.78 \%$ ), polychaete (Nerine cirratulus, $16.90 \%$ ), Brachyura (Dotilla myctiroides, $5.84 \%$ ) and polychaete (Glycera alba, $4.56 \%$ ). Such a dominancy of surf-bean clam Donax has earlier been reported from other beaches of Goa (Dwivedi et al. 1973, McLusky et al. 1975, Achuthankutty et al. 1978, Ayyappan Nair 1978).

Spatial community indices varied considerably from season to season at any given station (Table 1). This probably reflects the different reproductive periodicity of the dominant species such as Donax faba, Nerine cirratulus and Scottolana sp. Such variations in spatial distribution within intertidal sandy zones are due to beach slope, local current regime and reproductive periodicity of the invading species (McIntyre 1977). Species diversity increased from high to low water mark and was highest at low water mark (Table 1). Such an increase in community indices in a sandy intertidal zone also coroborates the findings of earlier workers (Vohra 1971, Croker 1977, Dexter 1979, Broom 1982). The diversity values are comparable with those of Rodrigues (1984) for a Goa beach and McLachlan (1977) for a South African beach. However, diversity values were relatively low as compared to the sub-tidal region of a tropical estuary (Parulekar et al. 1980) thus reflecting the general paucity of macrofauna on an estuarine sandy beach (Knot et al. 1983).

Temporal variation of community indices is shown in Fig. 2. In general these values increased from post- to premonsoon. Low values of species diversity during May 1981 and May 1982 were mainly due to the abundance of Donax faba and Scottolana sp. associated with low evenness. Such a condition is known as oligomixity (Dejong 1975) and was observed in the same months of both years. This probably reflects the
Table 1. Seasonal species diversity $\left(\mathrm{H}^{\prime}\right)$, evenness $\left(\mathrm{J}^{\prime}\right)$ and species richness (SR) at different stations $10 \mathrm{~m}$ and $50 \mathrm{~m}$ represent high and low water mark stations respectively)

\begin{tabular}{|c|c|c|c|c|}
\hline Season & $\begin{array}{l}\text { Stations } \\
(\mathrm{m})\end{array}$ & $\mathrm{H}^{\prime}$ & $J^{\prime}$ & $\mathrm{SR}$ \\
\hline Premonsoon & 0 & 2.96 & 0.89 & 0.41 \\
\hline \multirow[t]{5}{*}{ (Feb-May 1981) } & 10 & 1.51 & 0.50 & 0.72 \\
\hline & 20 & 1.52 & 0.66 & 0.41 \\
\hline & 30 & 1.39 & 0.60 & 0.41 \\
\hline & 40 & 3.47 & 0.85 & 1.64 \\
\hline & 50 & 2.67 & 0.93 & 0.62 \\
\hline Monsoon & 0 & 1.98 & 0.99 & 0.31 \\
\hline \multirow[t]{4}{*}{ (Jun-Sep 1981) } & 10 & 0.37 & 0.37 & 0.10 \\
\hline & 20 & 2.06 & 0.89 & 0.41 \\
\hline & 30 & 1.62 & 0.81 & 0.31 \\
\hline & 40 & 2.51 & 0.97 & 0.82 \\
\hline Postmonsoon & 0 & 2.37 & 0.84 & 0.62 \\
\hline \multirow[t]{5}{*}{ (Oct 1981-Jan 1982) } & 10 & 1.93 & 0.69 & 0.61 \\
\hline & 20 & 2.04 & 0.68 & 0.72 \\
\hline & 30 & 3.46 & 0.64 & 0.41 \\
\hline & 40 & 2.74 & 0.86 & 0.82 \\
\hline & 50 & 3.48 & 6.91 & 1.33 \\
\hline Premonsoon & 0 & 0.96 & 0.34 & 0.61 \\
\hline \multirow[t]{5}{*}{ (Feb-May 1982) } & 10 & 2.64 & 0.79 & 0.92 \\
\hline & 20 & 1.83 & 0.71 & 0.51 \\
\hline & 30 & 1.70 & 0.57 & 0.72 \\
\hline & 40 & 2.73 & 0.85 & 2.05 \\
\hline & 50 & 3.37 & 0.91 & 1.21 \\
\hline
\end{tabular}
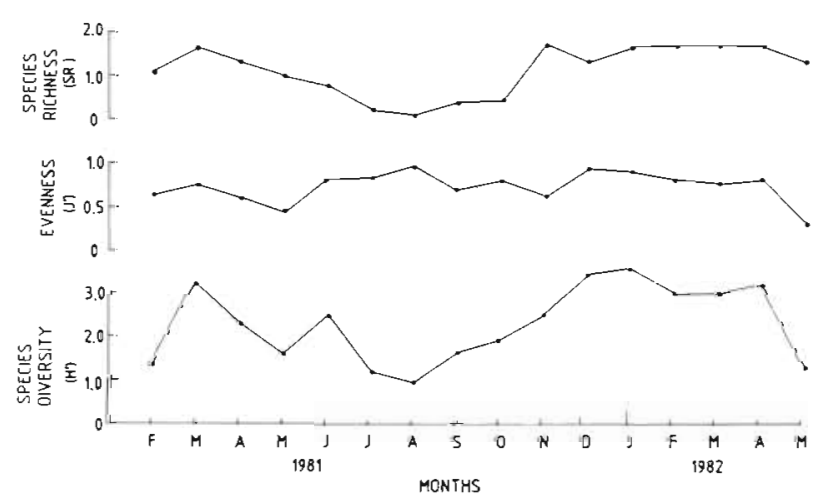

Fig. 2. Temporal variation of community indices

peak reproductive periodicity of these animals during these months. Table 1 and Fig. 2 show that diversity values are counterbalanced by the values of evenness and richness because these are interrelatd concepts (Pielou 1975). These changes are mainly brought by seasonal spawning of benthic invertebrates; other reasons may be environmental factors or biotic factors such as competition, predation and migration (Thorson 1966).

According to the species rank abundance (Table 2), different species occupy different ranks during the period of observation. Internal changes in rank of the 
Table 2. Temporal variation of ranks of species abundance for the 6 most abundant species

\begin{tabular}{|c|c|c|c|c|c|c|c|c|c|c|c|c|c|c|c|c|}
\hline \multirow[t]{2}{*}{ Species } & \multicolumn{11}{|l|}{1981} & \multicolumn{5}{|l|}{1982} \\
\hline & $F$ & $M$ & A & M & $\mathrm{J}$ & $\mathrm{J}$ & A & $\mathrm{S}$ & $\mathrm{O}$ & $N$ & $D$ & $\mathrm{~J}$ & $\mathrm{~F}$ & M & $\mathrm{A}$ & M \\
\hline Donax faba & 1 & 1 & 3 & 3 & 1 & 2 & 2 & 4 & 2 & 2 & 1 & 6 & 1 & 1 & 5 & 1 \\
\hline Nerine cirratulus & 2 & 2 & 4 & 2 & 2 & - & - & 2 & 1 & 3 & 2 & 1 & 2 & 2 & 2 & 2 \\
\hline Scotollana sp. & - & - & 2 & 1 & 4 & - & - & 3 & 3 & 1 & 6 & - & 4 & - & 3 & 5 \\
\hline Dotilla myctiroides & - & 3 & 1 & 4 & - & 3 & - & - & - & - & - & - & - & 4 & 1 & 3 \\
\hline Glycera alba & 5 & 5 & 5 & 5 & 3 & - & 1 & - & 4 & 4 & 3 & 2 & 3 & 5 & 4 & 6 \\
\hline Lineus sp. & 4 & - & - & 6 & 6 & 1 & - & 5 & - & 6 & 4 & 3 & 4 & 3 & 8 & 7 \\
\hline
\end{tabular}

6 most abundant species were discernible. Most of the time, Donax faba and Nerine cirratulus were the dominant species, only on a few occasions replaced by Dotilla myctiroides and Scottolana sp. (Table 2). The dominancy of $D$. myctiroides was recorded in the same month of both years (April 1981 and 1982). In a much more sheltered estuarine beach at Dona Paula, Goa, Rodrigues (1984) observed the abundance of the same species in July. Similarly D. faba exhibited dominance in the same months (February and March) in 2 successive years (Table 2). This possibly reflects the regular seasonal reproductive periodicity of these species.
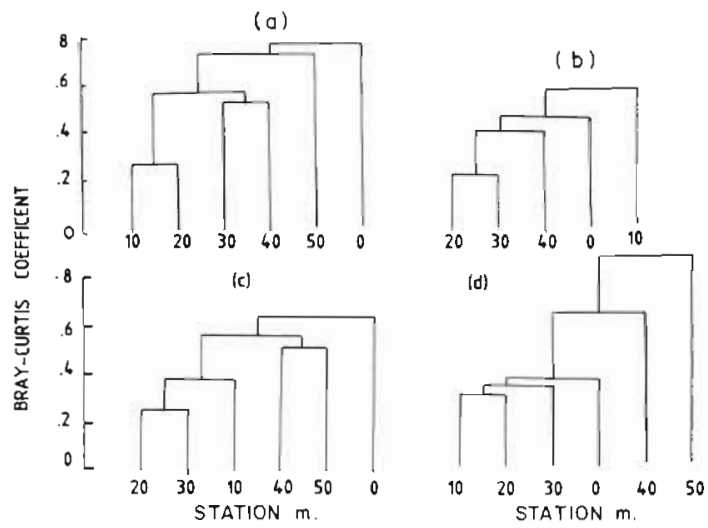

Fig. 3. Dendrograms illustrating seasonal relation between different station samples. 0 and $50 \mathrm{~m}$ represent high and low water mark stations respectively. (a) Premonsoon 1981; (b) monsoon 1981; (C) postmonsoon 1981-82; (d) premonsoon 1982

Normal cluster analysis grouped the samples into 2 or 3 groups which correspond to the zonation pattern (Fig. 3). Only the $0 \mathrm{~m}$ station is segregated from the cluster (Fig. 3a, c), possibly due to the presence of Ocypode ceratophthalma and Talorehestia spinipalma, which usually do not occur in the lower zones. The next cluster comprised mainiy of samples at 10,20 and $30 \mathrm{~m}$ stations (Fig. 3a, d). The fauna of this cluster comprised of Donax faba, Nerine cirratulus, Glycera alba and Dotilla myctiroides. The third group represents the remaining stations (Fig. 3c, d) and fauna included mainly polychaetes (Nereis spp., Clymene annadalei, Prionospio pinnata, Scoloplos marsupialis, Diapatra neopolitana, Nephthys dussumieri), crabs (Diogene avarus, Matuta lunaris, Emerita holthuisi), and molluscs (Nassa hepatica, Placenta placenta, Gafrarium pectinatum, Paphia textile). Such a zonal pattern distribution agrees with earlier observations (Vohra 1971, Parulekar 1973). However, the distributions of some species tend to extend to other zones (Fig. 3), illustrating the continuum concept of animal communities (Gray 1981).

Cluster analysis was also carried out to check the monthly samples grouped into 4 clusters corresponding to different seasons to show the seasonal pattern of species distribution (Fig. 4). Although 4 clusters were

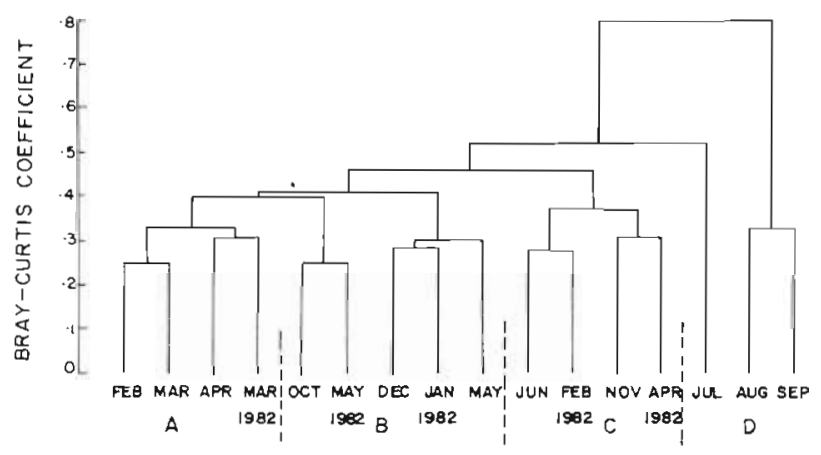

Fig. 4. Dendrograms illustrating relation between monthly samples. (A) Premonsoon; (B) post-monsoon; (C) premonsoon; (D) monsoon

apparent (Fig. 4A, B, C and D), these did not exactly reflect the seasonal clusters. The June sample grouped with Cluster $\mathrm{C}$ which corresponds to the premonsoon season. This was probably due to the observation being made before the onset of the southwest monsoon on June 5, and hence to the presence of premonsoon species like Glycera alba, Donax faba, Nerine cirratulus, Ocypode ceratophthalma and Lineus spp. Similarly some of the monthly samples tend to cluster with other seasons (Fig. 4). This is due to the extended distribution of some of the physiologically tolerant and biologically accomodative species during different 
seasons. However, each cluster (Fig. 3 \& 4) harbours a number of species which have narrow niches or are ecologically specialized (Gray 1981). The co-existence of these species is mainly attributed to the interaction of numerous biotic and abiotic factors (Pielou 1975). In a heterogenous habitat such as the intertidal region, where environmental characteristics vary both horizontally and vertically, multi-species communities, having cyclical patterns tuned with environmental changes, seem to be favoured.

Acknowledgements. The authors thank Dr. H. N. Siddiquie, Director for facilities and Dr. T. S. S. Rao for encouragement and reading the manuscript.

\section{LITERATURE CITED}

Achuthankutty, C. T., Sterling, A., Nair, S., Loka Bharathi, P. A., Menezes, Maria R. (1978). Sandy beach at Baina, Goa. Its ecology and production. Indian J. mar. Sci. 7: 23-29

Ayyappan Nair (1978). Production ecology of a tropical sandy beach at Benaulim, Goa. Indian J. mar. Sci. 7: 163-167

Boesch, D. F. (1973). Classification and community structure of macro-benthos in the Hampton Road area, Virginia. Mar. Biol. 21: 226-244

Broom, M. J. (1982). Structure and seasonality in a Malaysian mud flat community. Estuar. coast. Shelf Sci. 15: 135-150

Clifford, H. T., Stephenson, N. (1975). An introduction to numerical classification. Academic Press, New York

Croker, R. A. (1977). Macroinfauna of northern New England marine sand: long-term intertidal community structure. In: Coull, B. C. (ed.) Ecology of marine benthos. University of South Carolina Press, Columbia, p. 439-450

Davies, J. L. (1972). Geographical variation in coastal development. Oliver \& Boyd, Edinburgh

Dejong, T. M. (1975). A comparison of three diversity indices based on their components of richness and evenness. Oikos 26: 222-227

Dexter, D. M. (1979). Community structure and seasonal variation in intertidal Panamanian sandy beaches. Estuar. coast. Shelf Sci. 9: 543-558

Dwivedi, S. N., Rahim, R., Ayyappan, S. (1973). Ecology and production of intertidal sand fauna during southwest monsoon along the Mandovi estuary (Goa). In: Natarajan, R. (ed.) Recent researches in estuarine biology. Hindustan Publishing Corporation, Delhi, p. 1-20
Gray, J. S. (1981). The ecology of marine sediments. Carnbridge University Press, London

Harkantra, S. N. (1984). Studies on the intertudal ecology of the sand dwelling benthic community. Ph. D. thesis, Karnatak University

Harkantra, S. N., Parulekar, A. H. (1984). Intertidal benthic community ecology of sand-dwelling macroinvertebrates of Goa beaches. In: Thompson, M., Sarojini, R., Nagabhusanam, R. (ed.). Biology of benthic marine organisms. Technique and methods as applied to the Indian Ocean. Oxford and Indian Book House Publishing Corporation, New Dethi, p. 273-281

Knott, D. M., Clader, D. R., Van Dolah, R. F. (1983). Macrobenthos of sandy beach and nearshore environments at Murrells Inlet, South Carolina, USA. Estuar. coast. Shelf Sci. 16: 573-590

McIntyre, A. D. (1968). The meiofauna and macrofauna of some tropical beaches. J. Zool., Lond. 156: 377-392

McIntyre, A. D. (1977). Sandy foreshore. In: Barnes, R. S. K (ed.) The coastline. John Wiley and Sons, New York p. $31-47$

McLachlan, A. (1977). Composition distribution and biomass of the macrofauna and meiofauna of four sandy beaches. Zool. Afr. 12 (2): 279-306

McLusky, D. S., Nair, S. A., Stirling, A., Bhargava, R. M. S. (1975). The ecology of a central west Indian beach with particular reference to Donax incarnatus. Mar. Biol. 30: $267-276$

Parulekar, A. H. (1973). Studies on intertidal ecology of Anjdiv Island. Proc. Indian natn. Sci. Acad. 36 (B) 5: 611-631

Parulekar, A. H., Dhargalkar, V K., Singbal, S. Y. S. (1980). Benthic studies in Goa estuaries. Part III. Annual cycle of macrofaunal distribution production and trophic stations. Indian J. mar. Sci. 9: 189-200

Philip, K. P. (1974). The intertidal fauna of the sandy beaches of Cochin. Proc. Indian natn. Sci. Acad. 38 (B): 317-328

Pielou, E. C. (1975). Ecological diversity. Wiley-Interscience London

Rodrigues, C. (1984). Community structure of intertidal fauna at Dona Paula beach (Goa, India). Ph. D. thesis, University of Poona

Thorson, G. (1966). Some factors influencing the recruitment and establishment of marine benthic communities. Neth. J. Sea. Res. 3: 267-293

SokaI, R. K., Sneath, P. H. A. (1963). Principals of numerical taxonomy. W H. Freeman, San Francisco

Vohra, F. G. (1971). Zonation on a tropical sandy shore. J. Anim. Ecol. 40: 679-705

Accepted for printing on March 24, 1986 